\title{
Germination responses of Lehmann lovegrass to light
}

\author{
BRUCE A. ROUNDY, RAYMOND B. TAYLORSON, AND LEE B. SUMRALL
}

\begin{abstract}
Authors are associate professor, School of Renewable Natural Resources, University of Arizona, Tucson 85721; plant physiologist, U.S. Department of Agriculture, Agricultural Research Service, Beltsville, Maryland 20705; and graduate research assistant, Department of Civil Engineering, University of Missouri-Columbia, Columbia 65211.
\end{abstract}

\begin{abstract}
Lehmann lovegrass (Eragrostis lehmanniana Nees.) is a perennial, warm-season bunchgrass that is native to South Africa and has been seeded and spread naturally in the southwestern United States. Germination of 4 seed lots of varying age was tested in relation to darkness and irradiance with red (R) and far-red (FR) light. Germination was low in continual darkness, but greatly increased after exposure to $R$. Irradiation with $F R$ after exposure to $R$ reduced germination, confirming phytochrome involvement. Exposure to $\mathbf{R}$ after prolonged imbibition in FR did not increase germination of 1-2-year-old seeds and only slightly increased germination of older seeds. An alternating temperature of 16 hours at $15^{\circ} \mathrm{C}$ and 8 hours at $38^{\circ} \mathrm{C}$ greatly increased germination of seeds exposed to fluorescent light and slightly increased germination of seeds in darkness compared to a constant temperature of $25^{\circ} \mathrm{C}$. Greater seedling emergence of Lehmann lovegrass when the canopy is opened by burning, mowing, or grazing is likely a function of red light stimulation of biologically active phytochrome and increased seedbed temperature fluctuations.
\end{abstract}

Key Words: phytochrome, fire, grazing, grass canopy, seedbed ecology

Lehmann lovegrass (Eragrostis lehmanniana Nees) is a perennial warm-season bunchgrass considered to be subclimax on semiarid grasslands in the Northern Cape of South Africa (Fourie and Roberts 1976). It has been seeded extensively and has spread in areas of the southwestern United States and northern Mexico that are similar in temperature and summer rainfall to the Northern Cape of Southern Africa (Cox et al. 1988).

Fire is a natural phenomenon in these grasslands (Humphrey 1958, Tainton and Mentis 1984) and is also used as a management tool to decrease woody plant cover and increase herbaceous production (Pase 1971). Canopy removal by fire or mowing results in much higher seedling emergence of Lehmann lovegrass than occurs under intact canopies (Ruyle et al. 1988, Sumrall et al. 1991). Removal of a grass canopy not only increases diurnal temperature fluctuations (Savage 1980) but also changes the quality of light incident to the seedbed. Since vegetation transmits more far-red (FR) than red (R) light the $R$ / FR ratio is much lower under a plant canopy than in the open (Morgan and Smith 1981, Smith 1982). Low $R$ to $F R$ ratios or darkness may result in lack of appropriate phytochrome $\left(P_{\mathrm{fr}}\right)$ for germination (Franklin 1980). It could be hypothesized that seedling emergence of Lehmann lovegrass is increased after canopy removal as a result of increased germination of seeds exposed to red light.

Dark periods longer than 24 hours decreased germination of some Lehmann lovegrass accessions tested by Brauen (1967). Era-

\footnotetext{
Published as a contribution of the Arizona Agricultural Experiment Station.

Manuscript accepted 15 April 1990.
}

grostis ferruginea Beauv. exhibited a light requirement for germination that decreased with afterripening until germination was high even in darkness 16 months after harvest (Fujii and Isikawa 1962). Our objective was to determine the germination responses of Lehmann lovegrass to red and far-red light.

\section{Materials and Methods}

Four seed lots of differing age were tested for response to light quality (Table 1). All lots were collected in southern Arizona.

Table 1. Description of seed lots of Lehmann lovegrass from Southern Arizona tested for germination responses to quality of light.

\begin{tabular}{llll}
\hline \hline Name & Source & Year harvested & $\begin{array}{l}\text { Approximate age } \\
\text { when tested for } \\
\text { response to light }\end{array}$ \\
\hline PMC88 & $\begin{array}{l}\text { Soil Conservation Ser- } \\
\text { vice Tucson Plant } \\
\text { Materials Center } \\
\text { SR87 }\end{array}$ & 1988 & I year \\
& $\begin{array}{l}\text { Collected from the } \\
\text { Santa Rita Experi- } \\
\text { mental Range, 50 km } \\
\text { south of Tucson } \\
\text { NP9178 }\end{array}$ & 1987 & 2 years \\
& $\begin{array}{l}\text { Purchased from } \\
\text { Native Plants, grown } \\
\text { in southern Arizona } \\
\text { Purchased from } \\
\text { Native Plants, grown } \\
\text { in southern Arizona }\end{array}$ & Before 1986 & At least 3 years \\
\hline
\end{tabular}

Germination experiments were conducted by placing seeds of each lot on moistened filter paper in $9-\mathrm{cm}$ diameter petri dishes. There were 50 seeds of each lot placed in each of the 2 replicate petri dishes for each experiment and most experiments were conducted twice. All experiments but experiment 4 were conducted at $25^{\circ} \mathrm{C}$.

Experiment 1 was to determine germination responses to different periods of $R$ after imbibition in darkness. Seeds were imbibed in darkness for 24 hours, irradiated with $R$ for $0,1,5,20$, or 60 minutes, then returned to darkness and number of germinated seeds recorded after $\mathbf{5}$ days. Experiment $\mathbf{2}$ was to determine if $\mathbf{R}$ stimulation of germination was reversible by FR irradiance. Seeds were imbibed in darkness for 24 hours, and either left in darkness, irradiated with $R$ for $5 \mathrm{~min}$, irradiated with $R$ for $5 \mathrm{~min}$ then irradiated with FR for $5 \mathrm{~min}$, or irradiated only with FR for $5 \mathrm{~min}$. After these treatments, all seeds were returned to darkness and the number germinated counted after 5 days. Experiment 3 was to determine the effects of time of imbibition in dark or FR on germination for seeds subsequently left in darkness or irradiated with $R$. Seeds were imbibed in darkness or $F R$ for $0,8,24,48$, and 72 hours then either irradiated with $R$ for $5 \mathrm{~min}$ or not and germination was determined after seeds had been returned to 


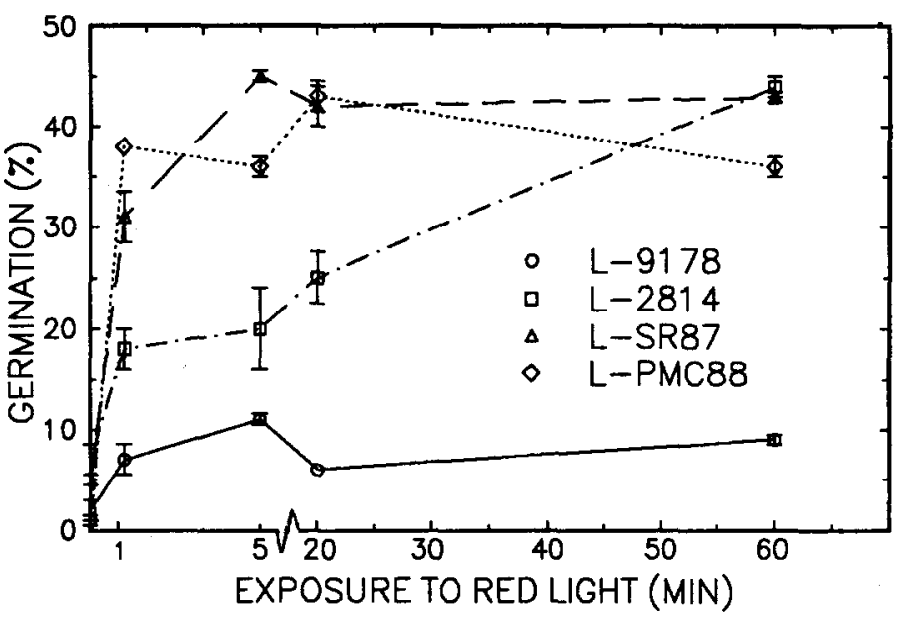

Fig. 1. Germination percentages of 4 lots of Lehmann lovegrass seeds after imbibition in darkness for $\mathbf{2 4}$ hours and subsequent irradiation with red light. Bars are equal to 1 standard error.

darkness for 5 days. Experiment 4 was to compare germination of seeds imbibed in darkness or light at constant and alternating temperatures. Seeds were imbibed in continual darkness or 16 hours of darkness and 8 hours of fluorescent light. For each of the 2 light treatments, seeds were germinated at a constant $25^{\circ} \mathrm{C}$ or at $15^{\circ} \mathrm{C}$ for 16 hours and $38^{\circ} \mathrm{C}$ for 8 hours. Germinated seeds were counted after 7 days.

Red or FR irradiations were from broad-band sources provided by red and infrared black light phosphor fluorescent lamps previously described by VanDerWoude and Toole (1980). Irradiances at seed level over the 400 - to $700-\mathrm{mm}$ region were $28 \mu \mathrm{mol} \mathrm{m}^{-1} \mathrm{~S}^{-1}$ as measured by a radiometer equipped with a quantum sensor.

\section{Results}

\section{Experiment 1}

Germination in darkness ( 0 min $R$ ) was low for all seed lots (Fig. 1). All seed lots had increased germination in response to $R$ irradiation but the response of lot 9178 was much less than the other lots. Lots SR87 and PMC88 were highly responsive to R. Germination increased greatly after only 1 -min exposure. Germination responses of all lots except 2814 saturated after only 5 -min exposure to $R$. This is fairly typical for a low flux phytochrome response [10 to $10,000 \mu \mathrm{mol} \mathrm{m}^{-2}$ of $\mathrm{R}$ (Kendrick and Cone 1985)].

\section{Experiment 2}

Germination was increased by $R$ irradiation but decreased by subsequent exposure to FR (Fig. 2). This FR reversion of Rstimulated germination confirms phytochrome involvement. Seed lot 2814, and especially lots SR87 and PMC88, had higher germination for seeds exposed to $R$ then FR or exposed only to FR than those in continual darkness. The lack of complete reversal by FR after $\mathbf{R}$ irradiance and increased germination of seeds irradiated only with FR may be a result of a small increase in Pfr phytochrome (1-3\%) that results from saturating FR irradiation. This indicates high sensitivity of some seeds of the several seed populations to small increases in $\mathbf{P}_{\mathrm{fr}}$.

\section{Experiment 3}

Germination was highest for seeds imbibed in darkness, then exposed to $R$ (Fig. 3). Germination response to $R$ increased with increased time to imbibition in the dark to 72 hours for lots 9178 and 2814 and to 48 hours for lots SR87 and PMC88. Even lot 9178, that had limited response to $R$ after 24 hours in darkness (Fig. 1 and Fig. 3), had greatly increased germination when exposed to $\mathbf{R}$ after 48 and 72 hours of imbibition in darkness. The decline in

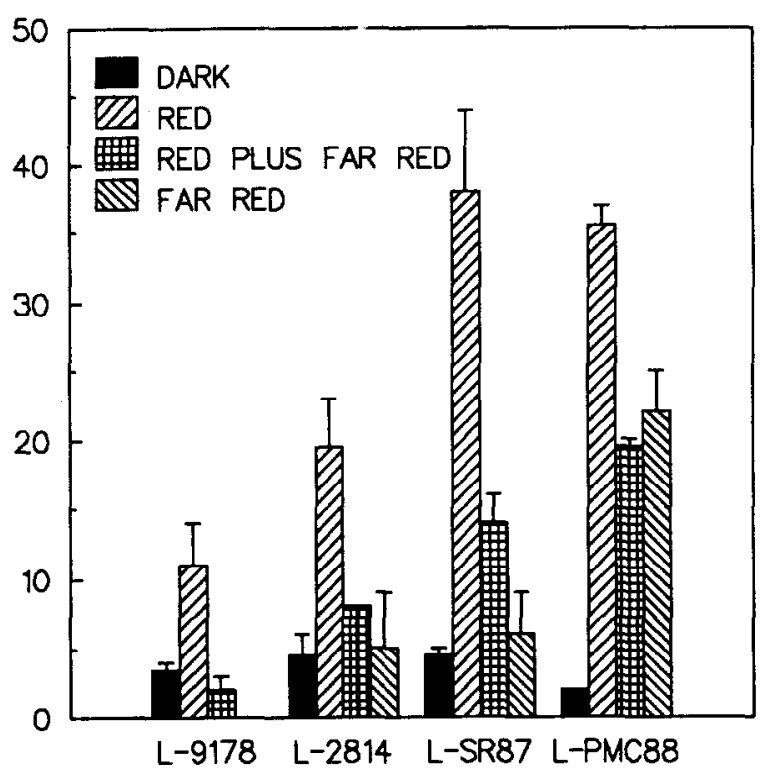

Fig. 2. Germination percentages of 4 lots of Lehmann lovegrass seed initially imbibed in darkness for 24 hours and subsequently left in darkness (dark), irradiated with red light for $5 \mathrm{~min}$ (red), irradiated with red light for 5 min then far-red light for 5 min (red plus far red) or irradiated only in far-red for 5 min (far red). Lines above bars equal 1 standard error.

germination of lots SR87 and PMC88 after 72 hours imbibition in darkness and subsequent exposure to $R$ suggests that a secondary dormancy may have been initiated in these seeds possibly associated with prolonged darkness. Seeds imbibed in darkness or FR and not exposed to $R$ had very low germination. Seeds imbibed in FR and then exposed to $R$ had increased germination compared to those not exposed to $R$, but this increase was much less than that for seeds imbibed in darkness, then exposed to R. Exposure to FR evidently decreases germination responsiveness to $R$ irradiation for these seeds.

\section{Experiment 4}

The interaction of lot, temperature, and light treatment was not significant $(P>0.05)$, indicating lots responded similarly to light and alternating temperatures. Exposure of seeds to fluorescent light greatly increased germination compared to seeds germinated in darkness (Fig. 4). Compared to constant temperature, alternating temperature slightly increased germination of seeds in darkness but more than doubled germination of seeds exposed to light.

\section{Discussion}

Our experiments show that Lehmann lovegrass seed germination may be inhibited by exposure to predominantly far-red light and by lack of red light. After imbibition in the dark for a short time (24 hours) germination of younger seeds (1-2 years old) was greatly stimulated by a very short exposure to $R$ (Fig. 1). Subsequent exposure to FR reversed the $R$ stimulation of germination (Fig. 2). Germination was low for seeds imbibed only in the dark or only in FR (Fig. 3). Exposure to R greatly increased germination of seeds after prolonged imbibition in darkness. However, exposure to $R$ after prolonged imbibition in FR did not increase germination of younger seeds ( $1-2$ years old) and only slightly increased germination of older seeds ( $>3$ years old). These germination responses to light may help explain seedling emergence differences in the field.

Temperate grasslands replace most of their above-ground biomass each year. A build-up of ungrazed or unburned biomass may 


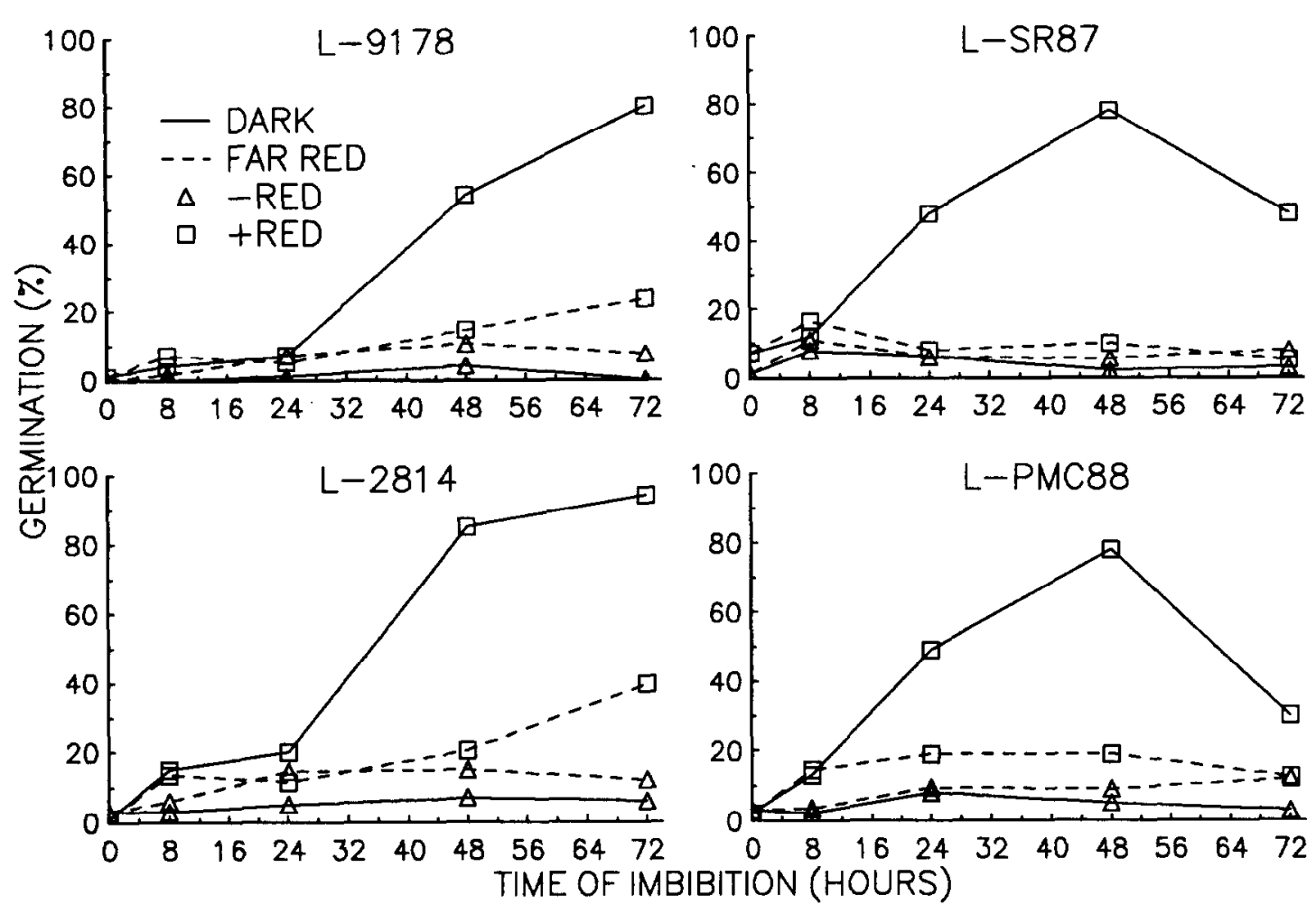

Fig. 3. Gemination percentages of 4 lots of Lehmann lovegrass seeds initially imbibed in darkness (dark) or far-red light (far red) for different periods of time and subsequently irradiated with red light for 5 min (+ red) or not (-red). Maximum standard error was $9 \%$ and the average standard error was $2 \%$.

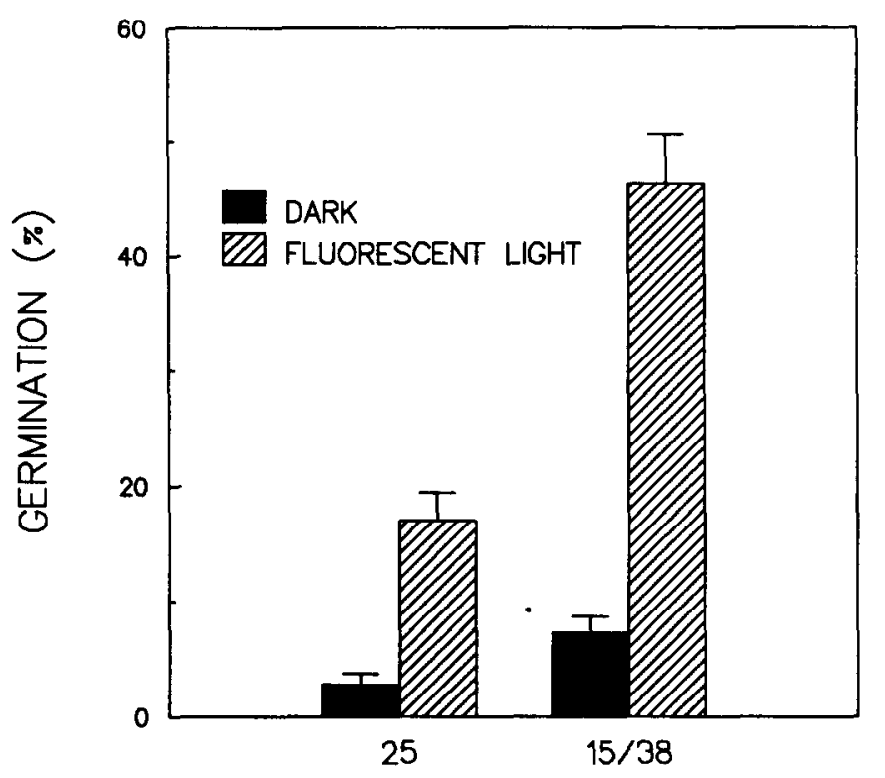

TEMPERATURE (C)

Fit. 4. Mean germination percentages of 4 lots of Lehmann lovegrass seed in relation to light and temperature treatments. The interaction of seed lot, light, and temperature was not significant $(p>0.05)$ so overall means of all 4 lots are presented. Lines above bars are 1 standard error.

not only shade and reduce photosynthesis of sub-canopy leaves (Caldwell et al. 1983) but may also intercept red light necessary to stimulate biologically active phytochrome (Pfr) and trigger germination of seeds in the seed bank.

The daytime light environment for seeds under a canopy of Lehmann lovegrass could include continual darkness, intermittent darkness alternating with intermittent $R$ or FR, continual FR or intermittent FR alternating with $R$. The exposure of seeds to these different light conditions depends on mature-plant density, accumulation of live and dead biomass, seed location, and sun angle. Our experiments suggest that seeds under litter or under a thick, live canopy and predominantly exposed to darkness or far-red light, respectively, will have limited germination. Germination of seeds in interspaces between established plants or in gaps in the canopy may be either stimulated or inhibited, depending on the length and sequence of exposure to predominately red or far-red light.

Ungrazed and unburned stands of Lehmann lovegrass accumulate a high cover of dead litter and have little seeding recruitment (Sumrall et al. 1991). Removal of the canopy by burning or mowing greatly increases seedling emergence (Sumrall et al. 1991). Although fire may kill mature Lehmann lovegrass plants, high seedling recruitment allows replacement of dead plants (Cable 1965, 1971; Ruyle et al. 1988). Heavy grazing, which keeps the canopy open, also may be associated with high seedling recruitment and more, but smaller, plants than in ungrazed areas (Cable 1971).

Removal of the canopy results in greater irradiance of red light and a greater temperature fluctuation in the seedbank than under intact canopies. Soil surface temperatures in a Lehmann lovegrass stand in Arizona during the summer establishment period diurnally fluctuated about $23^{\circ} \mathrm{C}$ when the canopy was removed by burning or mowing compared to a fluctuation of $10^{\circ} \mathrm{C}$ for an intact canopy (Sumrall et al. 1991). In the current study, alternating temperatures stimulated germination of seeds exposed to light much more than that of seeds in the dark (Fig. 4). Red light and alternating temperatures associated with open canopies both stimulate germination of Lehmann lovegrass and are both likely functional in the high seedling emergence that occurs after burning, mowing, or grazing.

Recommendations for seeding Lehmann lovegrass for range- 
land revegetation indicate seeds shoud be buried less than $6 \mathrm{~mm}$ (Jordan 1981). Cox et al. (1984) found no emergence of buried Lehmann lovegrass seeds in silty clay loam and sandy loam soils in the greenhouse. This lack of emergence may have been partly a result of lack of red light for germination. Winkel et al. (1991) found emergence of Lehmann lovegrass on a sandy loam soil in the field down to a depth of $6 \mathrm{~mm}$. Very little light penetrates below 2 $\mathrm{mm}$ in most soils (Kasperbauer and Hunt 1988). An average of $7 \%$ of the seeds in the 4 Lehmann lovegrass lots tested in the present study (Fig. 4) germinated in darkness. It could be suggested that only a small percentage of buried Lehmann lovegrass seeds actually germinate in the field. The small size of Lehmann lovegrass seeds probably allows them to have high seed soil contact and imbibition on the surface of wet soils where light is most favorable for germination.

\section{Literature Cited}

Brauen, S.E. 1967. Seedcoat histology, germination, dormancy and seedling drought tolerance of Lehmann lovegrass, Eragrostis lehmanniana Nees. PhD Diss. University of Arizona, Tucson.

Cable, D.R. 1965. Damage to mesquite, Lehmann lovegrass and black grama by a hot June fire. J. Range Manage. 18:326-329.

Cable, D.R. 1971. Lehmann lovegrass in the Santa Rita Experimental Range, 1937-1968. J. Range Manage. 24:17-21.

Caldwell, M.M., J.J. Dean, R.S. Nowak, R.S. Dzurec, and J.H. Richards. 1983. Bunchgrass architecture, light incerception, and water-use efficiency: assessment by fiber optic point quadrats and gas exchange. Oecologia 59:178-184.

Cox, J.R., and M.H. Martin. 1984. Effects of planting depth and soil texture on the emergence of four lovegrasses. J. Range Manage. 37:204-205.

Cox, J.R., M.H. Martin-R, F.A. Ibarra-F., J.H. Fourie, N.F.G. Rethman, and D.G. Wilcox. 1988. The influence of climate and soils on distribution of four African grasses. J. Range Manage. 4:127-139.
Fourie, J.H., and B.R. Roberts. 1976. A comparative study of three veld types of the Northern Cape: Species evaluation and yield. Proc. Grassl. Soc. So. Afr. 11:79-85.

Franklin, B. 1980. Phytochrome and seed germination. What's New Plant Physiol. 11:28-32.

Fujil, T, and S. Isikawa. 1962. Effects of after-ripening on photoperiodic control of seed germination in Eragrostis ferruginea Beauv. Bot. Mag. Tokyo 70:296-301.

Humphrey, P.R. 1958. The desert grassland: a history of vegetational change and an analysis of causes. Bot. Rev. 24:193-252.

Jordan, G.L. 1981. Range seeding and brush management on Arizona rangelands. T81121 Agr. Exp. Sta., Univ. of Arizona, Tucson.

Kasperbauer, M.J., and P.G. Hunt. 1988. Biological and photometric measurement of light transmission through soils of various colors. Bot. Gaz. 149:361-364.

Kendrick, R.E., and J.W. Cone. 1985. Biphasic fluence response curves for induction of seed germination. Plant Physiol. 79:299-300.

Morgan, D.C., and H.Smith. 1981. Non-photosynthetic responses to light quality. In: Lange, O.L., Nobel, P.S., Osmond, C.B. and Ziegler, H. (eds.) Physiological plant ecology I. Encyclopedia of plant physiology new series Vol. 12A. Springer-Verlag, N.Y.

Pase, C.P. 1971. Effect of a February burn on Lehmann lovegrass. J. Range Manage. 24:454-456.

Ruyle, G.B., B.A. Roundy, and J.R. Cox. 1988. Effects of burning on germinability of Lehmann lovegrass. J. Range Manage. 41:404-406.

Savage, M.J. 1980. The effect of fire on the grassland microclimate. Herbage Abstracts. 50:589-603.

Smith, H. 1982. Light quality, photoperception, and plant strategy. Annu. Rev. Plant Physiol. 33:481-518.

Sumrall, L.B., B.A. Roundy, and V.K. Winkel. 1991. Influences of canopy removal by burning and clipping on emergence of Eragrostis lehmanniana seedlings. J. Wildl. Fire. 1:34-40.

Tainton, N.M., and M.T. Menti. 1984. Fire in grassland. In: Booysen, P.V. and Tainton, N.M. (eds.). Ecological effects of fire in South African ecosystems. Springer-Verlag, N.Y.

VanDerWoude, W.J., and V.K. Toole. 1980. Studies of the mechanism of enhancement of phytochrome-dependent lettuce germination by prechilling. Plant Physiol. 66:220-224.

Winkel, V.K., B.A. Roundy, and D.K. Blough. 1991. Effects of seedbed preparation and cattle trampling on burial of grass seeds. J. Range Manage. 4:171-175. 